\title{
Sampling for Per- and Polyfluoroalkyl Substances (PFAS) by the Groundwater Ambient Monitoring and Assessment Priority Basin Project
}

\section{What are Per- and Polyfluoroalkyl Substances (PFAS)?}

Per- and polyfluoroalkyl substances (PFAS) are a family of more than 4,700 human-made chemicals that have been used in hundreds of products worldwide for decades (National Institute of Environmental Health Sciences, 2020). Some of the most wellknown PFAS are surfactants with a water-soluble (hydrophilic) functional group side and a water-insoluble (hydrophobic) side consisting of carbon atoms bonded to fluorine atoms (Buck and others, 2011). The carbon-fluorine bond is the strongest covalent bond in organic chemistry (Huang and Jaffé, 2019) and imparts chemical properties that help PFAS repel oil and water, reduce friction, and resist breakdown. These properties make PFAS useful for industrial applications (such as metal-plating) and for many consumer products such as carpeting, clothing, upholstery, nonstick cookware, food wrappers, and foams used to fight fuel fires. The same properties that make PFAS useful in these products also make them persistent in the environment. For this reason, they are sometimes called the "forever chemicals."

PFAS are released into the environment from a number of sources, including PFAS manufacturing plants, industries using PFAS, landfills (that receive PFAS-containing consumer products, food waste, and so on), wastewater treatment facilities, septic systems, and places where PFAS-containing foams were used such as at airports and military fire-training areas. PFOA (perfluorooctanoate), PFOS (perfluorooctanesulfonate), and other long-chain PFAS substances have been phased out from emissions and from products in the United States under the Environmental Protection Agency's PFOA Stewardship program (U.S. Environmental Protection Agency, 2006). Once PFAS are in the environment, they can affect groundwater and surface waters used as sources of drinking water. The removal of PFAS from drinking-water sources poses challenges unlike those of other groundwater contaminants due to their persistence and unique chemical propoerties (Newell and others, 2020).

PFAS have been detected in most environmental matrices including soil, precipitation, surface water, groundwater, biota, and in 97 percent of human blood samples (Lewis and others, 2015). Health risks associated with exposure to some PFAS include elevated cholesterol,

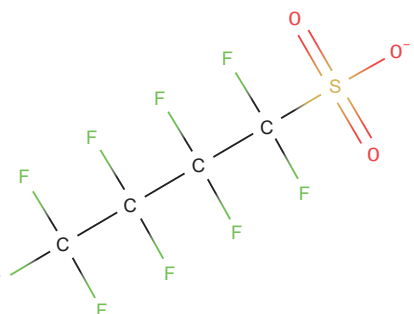

thyroid disorders, decreased vaccination response, and decreased birth weight (Danish Environmental Protection Agency, 2015). The California State Water Resources Control Board Division of Drinking Water (SWRCB-DDW) has established notification and response levels as health-based benchmarks for three PFAS (California State Water Resources Control Board, 2021b): perfluorooctanoate (PFOA), perfluorooctanesulfonate (PFOS), and perfluorobutanesulfonate (PFBS). If a chemical concentration is greater than its notification level in drinking water, the SWRCBDDW recommends that the utility inform its customers about health concerns associated with the chemical (California State Water Resources Control Board, 2021a). If the concentration is greater than the response level, the SWRCB-DDW recommends that the water source be taken out of service. Notification levels for PFOA, PFOS, and PFBS are 5.1, 6.5, and 500 nanograms per liter (ng/L), respectively; response levels are 10, 40, and $5,000 \mathrm{ng} / \mathrm{L}$, respectively.

\section{GAMA-PBP and PFAS}

The Groundwater Ambient Monitoring and Assessment Priority Basin Project (GAMA-PBP) began in 2004 as a collaboration between the U.S. Geological Survey (USGS) and the California State Water Resources Control Board (SWRCB) to provide a representative assessment of the quality of groundwater used for public and domestic supply (U.S. Geological Survey, 2013). In 2019, the GAMA-PBP added PFAS to the large list of chemicals analyzed in samples to assess the geographical distribution of PFAS in groundwater used for drinking water across all land-use settings. GAMA-PBP samples were analyzed by SGS Laboratory in Orlando, Florida, for 24 PFAS compounds that have a long history of use and are among the most commonly detected PFAS analytes in groundwater. In 2020, four more PFAS "replacement" compounds were added to the GAMA-PBP analyte list (table 1). Replacement PFAS are compounds that have been designed and synthesized to be less toxic than conventional PFAS compounds, but studies have not yet determined whether they are significantly less harmful either to the environment or to human health (Hopkins and others, 2018).

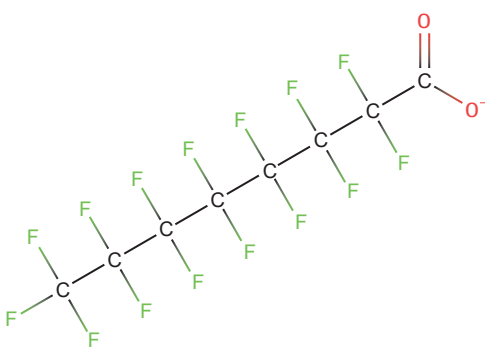


Table 1. Per-and polyfluoroalkyl substances (PFAS) analyzed in samples collected by the Groundwater Ambient Monitoring and Assessment Priority Basin Project (GAMA-PBP).

\begin{tabular}{|c|c|c|}
\hline Per- or polyfluoroalkyl substance & Abbreviation & $\begin{array}{l}\text { Detected } \\
\text { in GAMA } \\
\text { samples? }\end{array}$ \\
\hline Perfluorobutanoate & PFBA & yes \\
\hline Perfluorobutanesulfonate & PFBS & yes \\
\hline Perfluoropentanoate & PFPeA & yes \\
\hline Perfluoropentanesulfonate & PFPeS & yes \\
\hline Perfluorohexanoate & PFHxA & yes \\
\hline Perfluorohexanesulfonate & PFHxS & yes \\
\hline Perfluoroheptanoate & PFHpA & yes \\
\hline Perfluoroheptanesulfonate & PFHpS & yes \\
\hline Perfluorooctanoate & PFOA & yes \\
\hline Perfluorooctanesulfonate & PFOS & yes \\
\hline Perfluorononanoate & PFNA & yes \\
\hline Perfluorononanesulfonate & PFNS & no \\
\hline Perfluorodecanoate & PFDA & yes \\
\hline Perfluorodecanesulfonate & PFDS & no \\
\hline Perfluoroundecanoate & PFUnA & no \\
\hline Perfluorododecanoate & PFDoA & no \\
\hline Perfluorotridecanoate & PFTrDA & no \\
\hline Perfluorotetradecanoate & PFTeDA & no \\
\hline Perfluorooctanesulfonamide & FOSA & no \\
\hline $\begin{array}{l}\text { N-Ethylperfluorooctanesulfonamido- } \\
\text { acetate }\end{array}$ & N-EtFOSAA & no \\
\hline $\begin{array}{l}\text { N-Methylperfluorooctanesulfonamido- } \\
\text { acetate }\end{array}$ & N-MeFOSAA & no \\
\hline 4:2 Fluorotelomersulfonate & $4: 2 \mathrm{FtS}$ & no \\
\hline 6:2 Fluorotelomersulfonate & $6: 2 \mathrm{FtS}$ & yes \\
\hline 8:2 Fluorotelomersulfonate & $8: 2 \mathrm{FtS}$ & yes \\
\hline Perfluoro-2-propoxypropanoate & HFPO-DA* & no \\
\hline 4,8-Dioxa-3H-perfluorononanoate & ADONA* & no \\
\hline $\begin{array}{l}\text { 9-Chlorohexadecafluoro-3-oxanonane- } \\
\text { 1-sulfonate }\end{array}$ & F-53B Major* & no \\
\hline $\begin{array}{l}\text { 11-Chloroeicosafluoro-3-oxaundecane- } \\
\text { 1-sulfonate }\end{array}$ & $\begin{array}{l}\text { F-53B Mi- } \\
\text { nor* }\end{array}$ & no \\
\hline
\end{tabular}

*Replacement compound added to list of analytes in 2020.

\section{Preliminary PFAS Findings by the GAMA-PBP}

From May 2019 to September 2020, the GAMA-PBP collected PFAS samples from 107 public-supply wells and 104 domestic wells Statewide (fig. 1). Results for GAMA-PBP PFAS sampling are available in a data release (Kent, 2021). At least one PFAS was detected in 49 of these 211 samples ( 23 percent). Total concentrations of PFAS in these samples ranged from 1 to almost 70 nanograms per liter (ng/L), and of the 49 samples with detections, 17 of them (35 percent) had concentrations greater than $10 \mathrm{ng} / \mathrm{L}$ (fig. 1). PFAS were detected more frequently (fig. 2), and generally at greater concentrations (fig. 3), in samples from public-supply wells (detection frequency 36 percent) than in samples from domestic wells (detection frequency 11 percent).

Of the 28 individual PFAS analytes, 14 were detected in at least one GAMA-PBP sample at concentrations ranging from 1 to almost $16 \mathrm{ng} / \mathrm{L}$ (fig. 3). In general, the same PFAS compounds

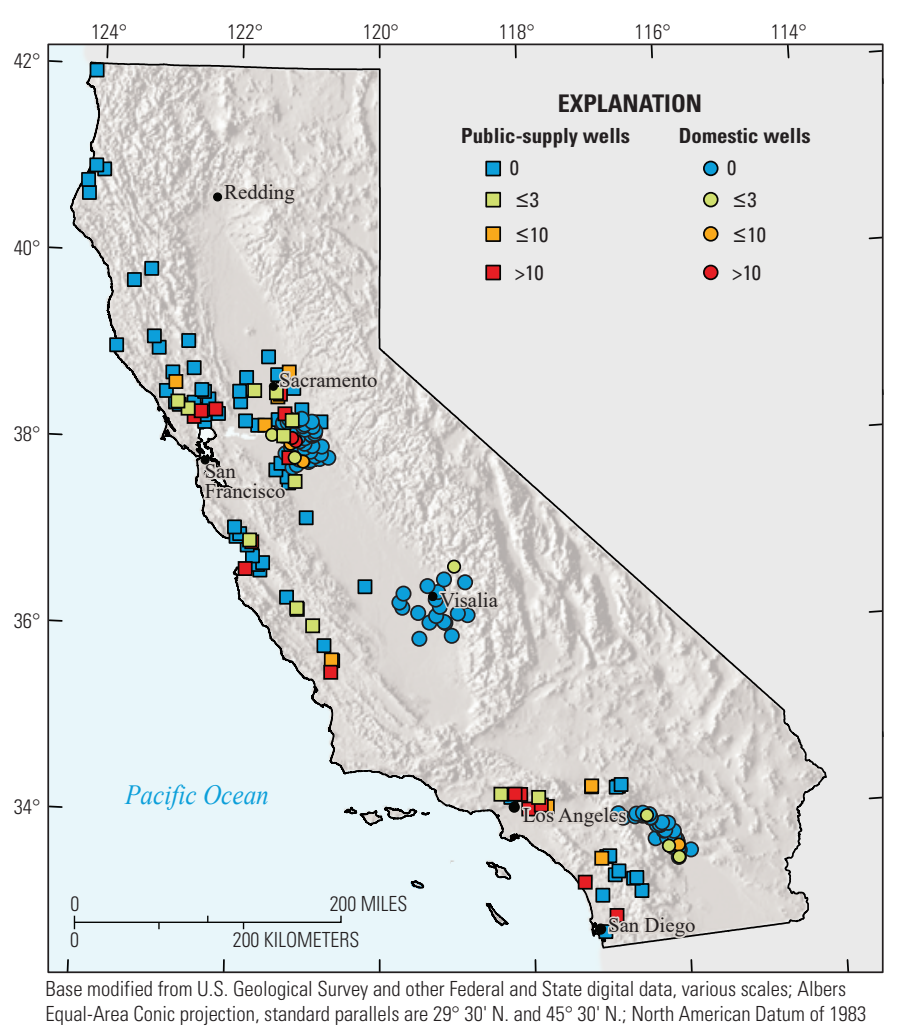

Figure 1. Total concentrations of per-and polyfluoroalkyl substances (PFAS) in nanograms per liter ( $\mathrm{ng} / \mathrm{L}$ ) in public-supply and domestic wells sampled by the Groundwater Ambient Monitoring and Assessment-Priority Basin Project (GAMA-PBP) from May 2019 to September 2020.

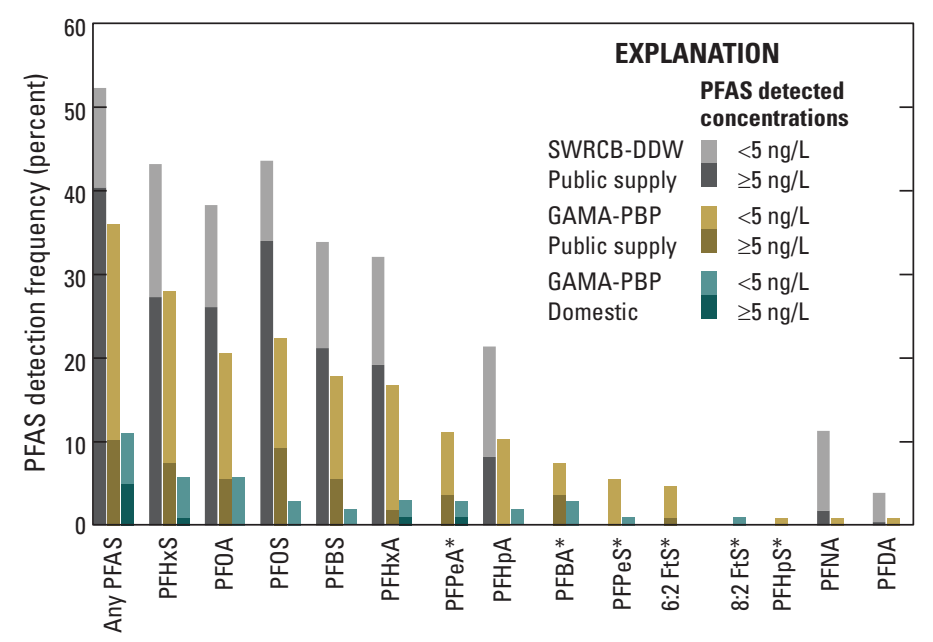

Figure 2. Detection frequencies of per-and polyfluoroalkyl substances (PFAS) in public-supply and domestic wells sampled for PFAS by the Groundwater Ambient Monitoring and Assessment-Priority Basin Project (GAMA-PBP) from May 2019 to September 2020 compared to mean detection frequencies from sampling of public-supply wells by the California State Water Resources Control BoardDivision of Drinking Water (SWRCB-DDW) during four quarterly sampling episodes from April 2019 to March 2020. A concentration of 5 nanograms per liter (ng/L) represents the target reporting limit required by the SWRCB-DDW for participating laboratories analyzing for these compounds. Compounds marked with an asterisk were not analyzed for the SWRCB-DDW. Full names of the compounds on the $\mathrm{x}$-axis can be found in table 1 . 


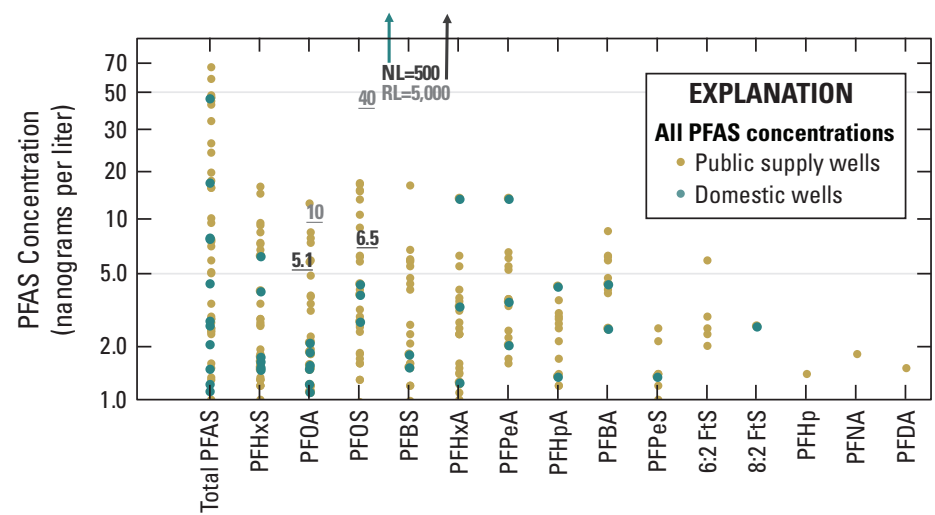

Figure 3. Concentrations of total and individual per-and polyfluoroalkyl substances (PFAS) detected in public-supply and domestic wells sampled for PFAS by the Groundwater Ambient Monitoring and Assessment-Priority Basin Project (GAMA-PBP) from May 2019 to September 2020. As of 2021, there are PFAS drinkingwater benchmarks only for PFOA, PFOS, and FPBS. The notification levels (NL) for PFOA, PFOS, and PFBS are 5.1, 6.5, and 500 nanograms per liter (ng/L), respectively, and response levels (RL) are 10, 40, and $5,000 \mathrm{ng} / \mathrm{L}$, respectively. Full names of the compounds here and on the $\mathrm{x}$-axis can be found in table 1 .

were detected in samples from public-supply wells and from domestic wells. Perfluorohexanesulfonate (PFHxS), detected in 17 percent of all samples, was the most frequently detected PFAS in the GAMA-PBP study (fig. 2). PFOA and PFOS were each detected in 13 percent of GAMA-PBP samples. PFOA, PFOS, and PFBS are the only three PFAS with health-based thresholds in California, and PFOA and PFOS are the most extensively used and researched PFAS. Concentrations exceeded the State notification levels for PFOA (5.1 ng/L) and PFOS (6.5 ng/L) in six and seven samples, respectively (fig. 3). The concentration of PFOA in one sample from a public-supply well exceeded the State response level of $10 \mathrm{ng} / \mathrm{L}$ (fig. 3). Perfluorobutanesulfonate (PFBS) and perfluohexanoate (PFHxA) were each detected in 10 percent of samples. PFBS concentrations in GAMA-PBP samples did not exceed the notification level of $500 \mathrm{ng} / \mathrm{L}$. The other nine PFAS were detected in less than 10 percent of samples.

The GAMA-PBP detected PFAS less frequently and at lower concentrations than a PFAS assessment completed by the California State Water Resources Control Board Division of Drinking Water (SWRCB-DDW). During quarterly sampling between April 2019 and March 2020, the SWRCB-DDW sampled more than 1,100 public-supply wells from one to four times, detecting at least one PFAS in about half of the wells (California State Water Resources Control Board, 2021b). The SWRCB-DDW study used several different laboratories that had varying analytical capabilities. Figure 2 shows detection frequencies for all detected PFAS and for samples with concentrations above and below the SWRCB-DDW required target reporting limit of $5 \mathrm{ng} / \mathrm{L}$, which was used to facilitate comparison among programs, well types, and compounds without bias caused by differing analytical sensitivities (California State Water Resources Control Board, 2021b). Most of the SWRCB-DDW PFAS detections exceeded the required target reporting limit of $5 \mathrm{ng} / \mathrm{L}$ (median about $8.0 \mathrm{ng} / \mathrm{L}$ ). In contrast, most GAMA-PBP detections did not exceed the required target reporting limit of $5 \mathrm{ng} / \mathrm{L}$ (median about $2.5 \mathrm{ng} / \mathrm{L}$ ).

Wells sampled in the SWRCB-DDW assessment were selected for monitoring because they are considered "hot spots" near known PFAS sources (such as landfills and airports) or near other wells with previous detections of PFOA or PFOS.
In contrast, the GAMA-PBP selects sampling sites in a spatially distributed manner to provide an unbiased assessment of groundwater quality in California. Therefore, PFAS are detected less frequently and at lower concentrations by the GAMA-PBP. Preliminary results from the GAMA-PBP representative-sampling strategy indicate that groundwater from most wells used for public and domestic supply in California does not have PFAS at concentrations above the detection limits for this study $(0.83-4.2 \mathrm{ng} / \mathrm{L})$.

\section{Ongoing PFAS Sampling by the GAMA-PBP}

This fact sheet presents preliminary results of PFAS sampling of public-supply and domestic wells by the GAMA-PBP between May 2019 and September 2020. GAMA-PBP sampling is ongoing and includes re-sampling a network of public-supply and domestic wells to monitor temporal variability ("trends" networks) and denser sampling of domestic wells in selected areas to assess the quality of groundwater resources used for domestic supply. Between October 2020 and September 2021, the GAMAPBP plans to collect samples from 130 public supply wells and about 120 domestic wells. By April 2024, GAMA-PBP plans to complete PFAS sampling for all of the public-supply trends networks, for five domestic trends networks, and for several more domestic well assessment areas (fig. 4). Because wells sampled by the GAMA-PBP are selected to be representative of ambient groundwater rather than targeted to investigate known or suspected contamination by PFAS, the GAMA-PBP dataset can provide information on the extent of PFAS in resources used for drinking-water supplies. In addition, GAMA-PBP sampling includes analysis of a broad suite of water-quality constituents and geochemical tracers and collection of ancillary data, and future work includes evaluation of processes that may be controlling the types and concentrations of PFAS in groundwater.

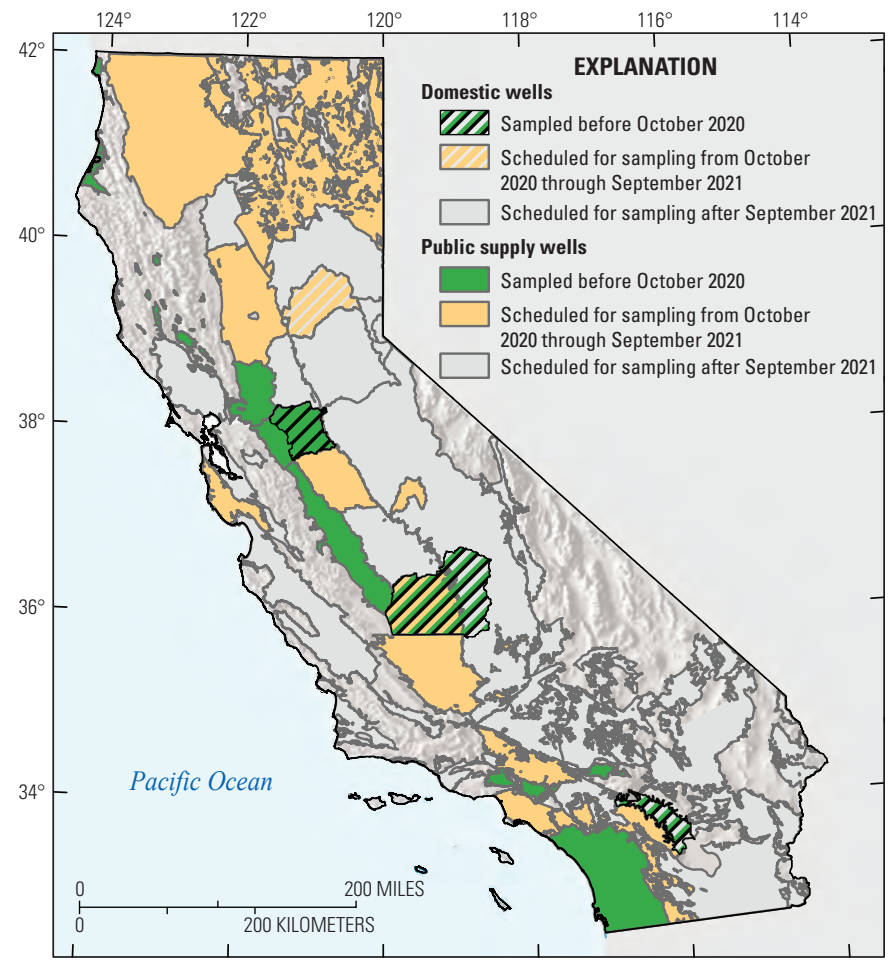

Base modified from U.S. Geological Survey and other Federal and State digital data, various scales; Albers Equal-Area Conic projection, standard parallels are $29^{\circ} 30^{\prime} \mathrm{N}$. and 45 $30^{\prime} \mathrm{N}$.; North American Datum of 1983

Figure 4. Groundwater Ambient Monitoring and AssessmentPriority Basin Project (GAMA-PBP) sampling schedule for per-and polyfluoroalkyl substances (PFAS). 


\section{Selected References}

Buck, R. C., Franklin, J., Berger, U., Conder., J. M., Cousins, I. T., de Voogt, P. Jensen, A. A., Kurunthachaleam, K. Mabury, S. A. and van Leeuwen, S. P. J., 2011, Perfluoroalkyl and polyfluoroalkyl substances in the environment: terminology, classification, and origins: Integrated Environmental Assessment Management v. 7, no. 4, p. 513-541.

California State Water Resources Control Board, 2021a, Drinking Water Notification Levels and Response Levels: An Overview (updated March 5, 2021), 17 p., https://www. waterboards.ca.gov/drinking_water/certlic/drinkingwater/ NotificationLevels.html

California State Water Resources Control Board, 2021b, PFAS|Per-and Polyfluoroalkyl Substances (updated April 13, 2021), https://www.waterboards.ca.gov/pfas/

Danish Environmental Protection Agency, 2015, Perfluoroalkylated substances: PFOA, PFOS and PFOSA: Evaluation of health hazards and proposal of a health based quality criterion for drinking water, soil and ground water, Environmental project No. 1665, https://www2.mst.dk/Udgiv/ publications/2015/04/978-87-93283-01-5.pdf

Hopkins, Z. R., Sun, M. DeWitt, J. C., Detlef, N. C., and Knappe, D.R.U., 2018, Recently detected drinking water contaminants: GenX and other per and polyfluoroalkylether acids: Journal of the American Water Works Association, v.110, no. 7, p. 13-28.

Huang, S., and Jaffé, P. R., 2019, Defluorination of perfluorooctanoic acid (PFOA) and perfluorooctane sulfonate (PFOS) by Acidimicrobium sp. Strain A6: Environmental Science \& Technology v. 53, no. 19, p. 11410-11419.

Kent, R., 2021, Datasets for sampling for per-and polyfluoroalky substances (PFAS) by the GAMA Priority Basin Project (GAMA-PBP): U.S. Geological Survey data release, https://doi.org/10.5066/P92IPRJD
Lewis, R. C., Johns, L. E. and Meeker, J. D., 2015, Serum biomarkers of exposure to perfluoroalkyl substances in relation to serum testosterone and measures of thyroid function among adults and adolescents from NHANES 2011-2012: International Journal of Environmental Research and Public Health, v. 12, no. 6, p. 6098-6114.

National Institute of Environmental Health Sciences, 2020 Perfluoroalkyl and polyfluoroalkyl substances (PFAS), https://www.niehs.nih.gov/health/topics/agents/pfc/index.cfm

Newell, C. J., Adamson, D. T., Kulkarni, P. R., Nzeribe, B. N., and Stroo, H., 2020, Comparing PFAS to other groundwater contaminants: Implications for remediation: Remediation, v. 30 , no. 3 , p. $7-26$.

U.S. Environmental Protection Agency, 2006, Assessing and Managing Chemicals under TSCA-Fact Sheet: 2010/2015 PFOA Stewardship Program, https://www.epa.gov/assessingand-managing-chemicals-under-tsca/fact-sheet-20102015pfoa-stewardship-program

U.S. Geological Survey, 2013, Ground-Water Ambient Monitoring and Assessment Program: U.S. Geological Survey Fact Sheet 2004-3089, 4 p.

\section{Acknowledgments}

This study was supported by funds from the California State Water Resources Control Board. We thank the field crews for the collection of samples and the well owners who graciously allowed the U.S. Geological Survey to collect samples from their wells. Contributions by peer reviewers Dr. Andrea Tokranov of the USGS New England Water Science Center and Jeannine Larabee of the Santa Clara Valley Water District are greatly appreciated.

By Robert Kent

\section{GAMA-PBP reports and data can be obtained from}

GAMA-PBP Project Chief

U.S. Geological Survey

California Water Science Center 6000 J Street, Placer Hall

Sacramento, CA 95819-6129

Telephone: (916) 278-3000

http://ca.water.usgs.gov/gama
GAMA Program Unit

State Water Resources Control Board Division of Water Quality 1001 I Street, Floor 15 Sacramento, CA 95814

Telephone: (916) 341-5455 http://www.waterboards.ca.gov/gama 